\title{
4
}

\section{Autistic People Against Neuroleptic Abuse}

\author{
Dinah Murray
}

\section{Origins}

In the mid-90s I had a job as a support worker for people with severe and multiple learning (intellectual) disabilities including autism, who had been discharged from National Health Service (NHS)-run long-stay hospitals into "the community." Our training for this job was thorough and humane in many ways, but little was said about the stacks of ring-bound blister packs of pills kept under lock and key. A community pharmacist explained to us how to administer the pills in the right order at the right time with proper regard to hygiene and record keeping. Nothing was more important, it seemed.

At first I took it for granted there were good reasons for all the pills: after all, these people had come out of hospitals. However, after a while I noticed that thioridazine was one of the "medications" and it rang a bell as one of the "old, dirty" antipsychotics aka "major tranquilizers" — wellknown to cause severe movement disorders inter alia. I started looking up

D. Murray (凶)

London, UK 
the other drugs, then someone left this photocopied article in the office about the use of antipsychotic drugs with adults with learning disabilities and challenging behavior. These disabled people were being deliberately sedated with extremely harmful drugs.

One night the young manager, in tears, told me she'd just discovered that one of our most severely disabled people, who had gone into the old institution when he was 4 or 5 years old, had ridden his tricycle into the long stay hospital where he had then lived - and been drugged with major tranquilizers - for 40 years. We knew him as someone who needed help even to turn over. The period when our people had been hospitalized was a period of excited experimentation with new drugs and the doctors really had no idea what they were doing when they prescribed doses of chlorpromazine (an antipsychotic) to children which would later be regarded as around twelve times the recommended maximum. I was in tears too.

I became obsessed with the medication. It was increasingly clear that we were looking at routine, unquestioned, administration of substances that everybody in the know knew to be dangerous, to people that everybody in the know knew to be powerless: the rage drove work lasting into the twenty-first century.

As I got deeper into the general research I was doing, I became more and more horror-struck by the great range of problematic features of the whole psychotropic prescribing business, which were stripped bare in the power structures in which people with no information and no voice were ultimately vulnerable. I discovered that the drugs had a negative impact on hormones, insulin, dopamine, teeth, all drives including sex drive; I discovered these drugs kill people as well as twisting their limbs; I discovered that there was a long-term cumulative harmful impact and that the movement disorders many develop include a terrible restlessness, emotional and physical, as well as catatonia-like loss of function and uncontrollable tongue and limb movements; that polypharmacy — multiple prescribingwas often to counter iatrogenic impacts of other drugs; that it had long been known that previously sane monkeys had gone bonkers after being dosed with a neuroleptic for several months which was suddenly withdrawn, causing not "relapses" but discontinuation syndrome, and gradual withdrawal was strongly recommended but rarely followed; that people were being medicated for distressing events and their signs of misery were 
seen as challenging instead of them being helped to deal with their understandable grief and upset; that urinary incontinence was a possible adverse effect (with huge social consequences) that was regarded as insignificant; that lactation was sometimes triggered, even in males; that weight gain to the point of obesity was shrugged off in the research but punished in the kitchens by stricter diets and locked cupboards. Worse still, all claims of "successful outcomes" were based on reductions in behavior of various sorts - given the usual sedating effects of the major tranquilizers, their ability to reduce behavior was unimpressive- the sedative effect wears off after 6-8 weeks, few studies at that time lasted longer than 6-8 weeks (see Fig. 4.1).

So I left my regular job and signed on as a relief worker, a casual worker status that meant I could never be asked to distribute medications. This also gave me more time for research and to develop a campaigning website. Thanks to pharmacologist Paul Shattock who told me about it-he was publicly concerned about the use of neuroleptics for behavior control long

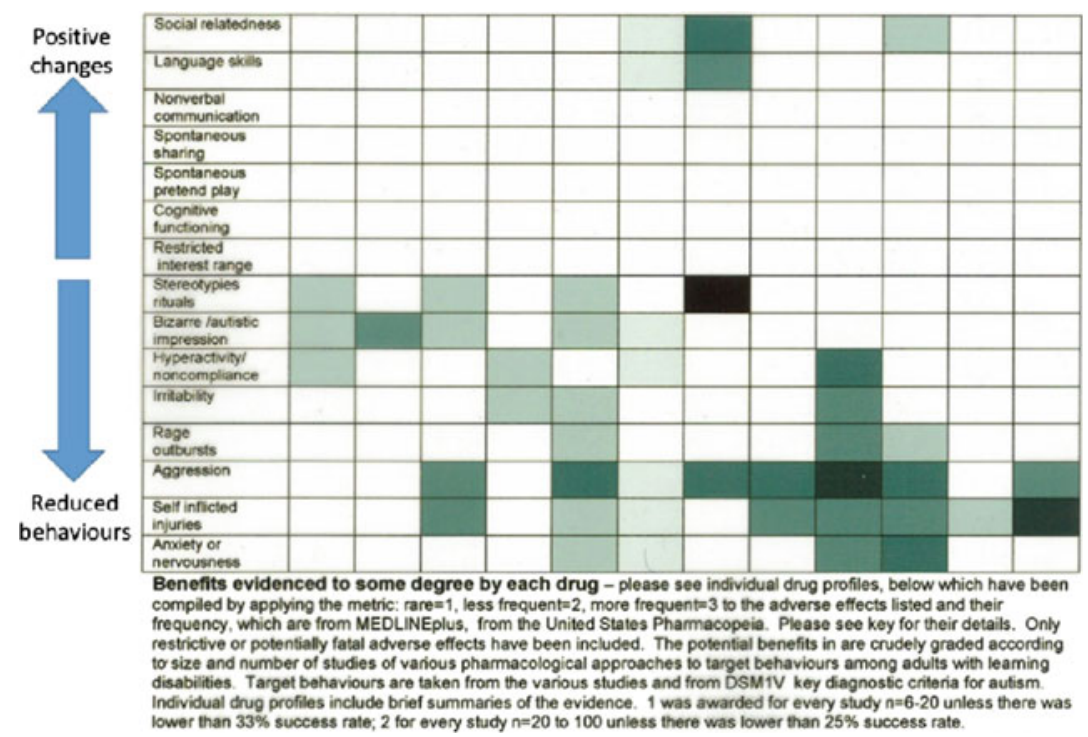

Fig. 4.1 The chart clearly showed that the vast majority of claimed "benefits" of medication in this sphere are about reducing behavior rather than enhancing personal well-being or capacity 
before his public support for Andrew Wakefield's dubious research into the MMR vaccine-I went to an Autism Europe Conference in Brussels and heard about their Code of Good Practice on Prevention of Violence against Persons with Autism [1]. Paul also introduced me there to a concerned mother from the UK; meeting her at that conference was the first necessary step toward getting some activists working together in the tiny and unstructured group we called Autistic People Against Neuroleptic Abuse, or APANA for short.

The point of APANA was to be an effective vehicle to raise awareness of the harms being done to vulnerable people in the name of care, and to penetrate some entrenched positions in huge and deep-rooted power structures. For people with access (not the subjects of my case studies!), the Internet proved a rich source of information about both government and NGO thinking on these and related issues: there were consultations, and guidelines, and that was one way to get one's voice heard.

\section{Getting to Work and Forming Alliances}

APANA recruited two autistic people: as Chairperson, David Andrews, who was in the process of acquiring several psychology-related qualifications; as Patron, Wendy Lawson (now known as Wenn Lawson), who was well along a similar path. The rest of the team were all parents of adult offspring they had seen damaged by psychiatrictreatment. I was spending more and more time reading research (for example, [2-6]). I discovered that an unexpected result of the hospital closures was that prescriptions of psychotropics had gone up as neighbors of the new noisy people in the community complained. When I looked into the old prescription records, I found that this was true for almost everyone in the houses where I most often worked. The institutions had eventually had a policy of reducing medication.

There was one discovery in the files that tipped my concern from a commitment to an out-and-out mission. A service user I'll call Patrick, who was on the highest neuroleptic dose I found in this group, had become borderline catatonic. From the files it was clear that he had once been fairly lively. Then I found a letter, addressed to senior management from 
the "community" learning disability psychiatrist. She complained in her letter that support workers had questioned her judgment that Patrick's medication should be increased by $30 \%$. Since the rules that govern care providers explicitly require them to follow all medical advice or put their business at risk, this reproach was significant and probably got some caring and conscientious workers into a bit of trouble. Much worse though were the repercussions for Patrick: the psychiatrist had increased his dose by $50 \%$ after her authority had been questioned in this outrageous way; without prompting he was no longer able even to complete the action of putting a kettle on to boil. It is ironic that "health and safety" risk aversion in social care settings led to routine, authorized, high-risk behavior by both staff and management toward the people receiving their "care."

I discovered that distinguished psychiatrist Lorna Wing was interested in autism and catatonia, and had expressed concerns that neuroleptic prescribing was sometimes implicated in its onset. So I rang Lorna Wing's Centre, then known as the Centre for Social and Communication Disorders, in the hopes of speaking to her. She was not there that day but Judith Gould came to the phone to deal with this unknown support worker's anxious query. She listened to the problem, immediately said I should ring Lorna Wing herself and gave me her home phone number. So next I picked up the phone and dialed that. The great Wing answered the phone herself and was so interested and open that I trusted her at once and said very soon after our conversation began, that all I had found among her colleagues was "Arrogance, ignorance, and hypocrisy" - to which, taking my breath away, she replied with vigor, "I couldn't agree more!" One couldn't hope for a better ally in this particular battle [7].

\section{Communicating Our Message Across Many Platforms}

I decided to write up case studies of what I'd found in the files in a way that would make the research as effective as possible. I looked at quality of life issues and the impact on those of the ramified adverse effects of the prescribed drugs; I compiled detailed timelines for four service users, three of them autistic, and their life events [8]. 
Unfortunately, how to carry out quality of life assessments objectively remains a vexed question to this day [9], so instead I took and followed advice on assessing relevant costs, such as travel and staff time, in British pounds and went back through the records adding actual costs or rulegoverned estimates of costs to the timelines.

Our website, run by my friend Sue Craig, had much factual information, including all the illustrations to this chapter, and useful links and ancient advertisements for old drugs and new. Canadian artist Ralph Smith designed an elegant logo for us (Fig. 4.2). This served us well and got the message out that Autistic People Against Neuroleptic Abuse was an active force. Autistic activists in the USA such as A. M. Baggs (now

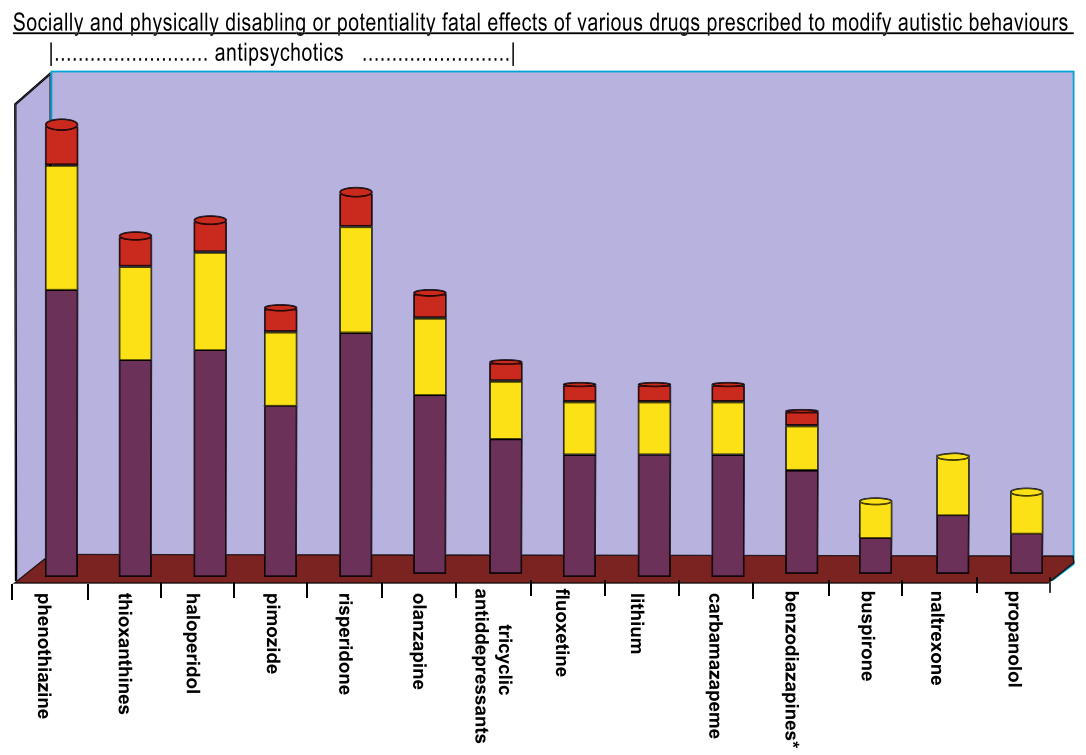

$\square$ socially disabling or stigmatising effects $\square$ physically disabling effects $\square$ potentially fatal effects

Fig. 4.2 Summarized comparisons of restrictive or potentially fatal effects of psychotropic drugs prescribed for autistic adults with learning disabilities and challenging behavior (ca 2001). From left to right, starting with the antipsychotics: phenothiazines (e.g. Chlorpromazine), thioxanthines (e.g. Fluenthixol), Haloperidol, pimozide, risperidone, olanzapine; and then various non-neuroleptic experimental drugs for autism-related perceived problems, viz paroxetine, lithium, carbamazepine, buspirone, naltrexone, and the beta-blocker propranolol 
known as Mel Baggs) and Kassiane Sibley (now Kassiane Asasumasu) were supportive and deepened my understanding of what it is like to be on the receiving end of interventions designed solely for the purpose of suppressing behavior which other people condemn.

Being able to brand the work as from "APANA" was I think particularly helpful in being taken seriously rather than assimilated into the vox populi. Mencap, the main British learning disabilities charity, agreed to circulate the research to their consortium of service providers in this field.

It also helped that I had some strategically placed friends and allies. David Branford, a senior learning disabilities pharmacist, was sympathetic, and encouraged me to attend a conference he was organizing in Leicester late last century. It was there I first encountered the "psychiatry is to real medicine as astrology is to astronomy" meme, inadvertently shared with me by a psychiatrist who misjudged my status until rather late in our conversation, assuming I was a fellow clinician.

Rita Jordan at Birmingham University gave me a platform for the medication issues on one of the Autism Distance Education Course weekends, thus reaching everyone doing the course at that time. Almost all of those were professionals in the field, some in senior positions, including people who worked with adults. Glenys Jones was in the process of setting up a new, practical, autism-relevant journal, Good Autism Practice, and she invited me to submit my research for the prototype issue, published in 1999. I also got a poster presentation at the Autism Europe Conference in Glasgow that year and Wen Lawson and/or I were there in person throughout ready to discuss it.

\section{Pressing Parliament and Leaning on the Law}

I undertook a careful analysis of a range of medications proposed at the time for "ameliorating autistic behavior," and I scored adverse effects according to their recognized frequency (using the free Medline database). Risperidone, newly popular with prescribers, was only slightly less harmful than chlorpromazine at the recommended (likefor-like) dose ranges for psychosis (see Fig. 4.3). Wenn Lawson and myself addressed a sub-committee of the All-Party Parliamentary Group 


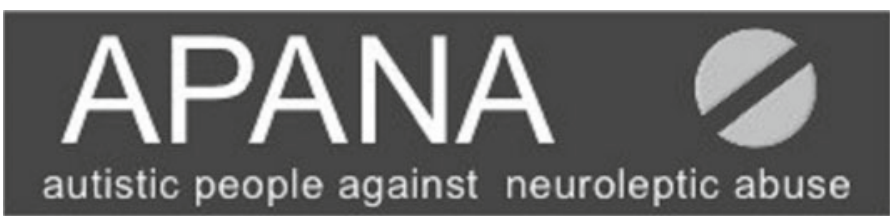

Fig. 4.3 The APANA logo, designed by Ralph Smith

on Autism about prescribing, illustrated with Fig. 4.1. (One of the people who heard us was Virgina Bovell, a mother of an autistic person with learning disabilities, in whom we found a new ally despite her involvement with behaviorism-I later came to understand that parents may be presented with behavioral approaches as the only alternative to a medicalized attitude and recourse to drugs.)

I got views from as many as possible autistic people with relevant experience and discovered that some, but not all, were saying that at a very low dose, they found risperidone positively helpful; that it improved their mood and could make social encounters less stressful. If someone tells me that they find a drug helpful and their consumption is moderate, I'm going to see that as normal human practice. In the case of risperidone or other antipsychotics, I liken this to accepting that a glass of wine every day may do a lot of good, while a bottle will not. To me it is the absence of choice, the absence of relevant information, and the inability to refuse that need fixing. In the long run, it is worth noting that most of the people I knew who liked risperidone at a low dose eventually developed adverse effects that put them off-they were fortunate to have the capacity to articulate their problems and the autonomy to make this decision.

(Having now, two decades later, read through extensive messages posted in the last few years on mental health forums, it is clear that low dosing with risperidone has become commonplace, especially for anxiety. It is also clear that there is a major division in people's experiences of this drug, with some people greeting its effects with joy and others with real horror. To give something as powerful and unpredictable as this to people who are unable to tell you how they feel, still seems to me the height of irresponsibility. People need to understand the potential risks and freely 
choose to take them. Clearly that did not apply to the people in my case studies!)

Though our message was being heard in some quarters, the extreme power imbalance sometimes seemed overwhelming. So we decided to keep pushing positive proposals tied to precisely referenced and cited government papers, by addressing civil servants, administrators, and Members of Parliament about the law with some specific suggestions that I set out at length. These are to be found following the main text of my "Potions and Pills" piece [8] in the longer version online.

A related line I decided to follow was to get a proper legal view pro bono (for no fee because for the public good) if possible. Somehow I found a deeply committed solicitor, Karen Ashton, and barrister Paul Bowen of the Doughty Street Chambers in London, who were willing to look to assess the legal situation vis-à-vis medical treatment that flouts the Hippocratic Oath, Do No Harm-especially to people deemed to be "mentally incapacitated." They needed someone to gather the evidence together and I gave up my job entirely for three months, during which I created a compendium of abstracts substantiating a great variety of adverse effects and at the same time demonstrating that reduced behavior was the key index of "efficacy" in their use (see Fig. 4.1). This resulted in lawyers Bowen and Ashton producing a discussion paper (available in the online edition of this chapter), which suggested that medical treatment can amount to an assault unless great care is taken regarding consent or "best interests." They proposed that the Human Rights Court "may well be willing to exercise its power in relation to the prescribing of psychotropic drugs, particularly where serious side-effects are well-established." This was circulated widely.

In 2001, Ashcroft and colleagues [10] called for better research into antipsychotic prescribing for "challenging behaviours." They cited Brylewski and Duggan's [11] Cochrane Review, as showing "over 500 citations assessing the impact of antipsychotic drugs on challenging behaviour. Of these only three were methodologically sound randomised controlled trials, but even these were unable to show whether antipsychotic drugs were beneficial or not in controlling challenging behaviour" [10]. 


\section{Impact}

Ashcroft and colleagues frame the issues thus: "People with learning disability sometimes display challenging behaviour. This can be managed by use of antipsychotic medication or behavioural therapy or both. There is no solid evidence, however, that these therapies are safe and effective." Unfortunately the possibility that behavioral therapy may not be safe was not pursued, nor was the possibility that a focus on behavior control cannot preserve mutuality, create trust, or be authentically "person-centered." This fixation with behavior, along with skillful marketing of "Positive Behaviour Support," has underpinned and undermined a medical campaign against the drugging launched in 2018 (see below).

Consent issues and the best interest concept were soon to be leading themes in the Mental Capacity Act (2007), (a development to which Paul Bowen contributed). That is a very strong piece of rights legislation in principle, though it has thrown up some paradoxes in practice (see, e.g., DoLS discussion at House of Lords 2015, or this Parliamentary video from 2018, https://www.parliamentlive.tv/Event/Index/d47bf41e-72b148d8-afc5-b5727a40f05b). The MCA guidelines draw attention to the possibility that the psychotropic effects of some medications may hinder judgment, and there are widespread guidelines on administering medication to people whose best interests must in law be factored in. In 2006 the University of Birmingham published an attempt to address the consent issues by creating a simplified symbol-based system for describing the medications and their effects [12]. Perhaps our activities contributed to the wider recognition of such needs, but how much long-term impact did we have?

Maybe a bit for a while-however, see this from the Foreword of the Faculty of Learning Disabilities of the Royal College of Psychiatrists [13]:

There is compelling evidence that a significant number of people with intellectual disabilities are prescribed psychotropic medication that, at best, is not helping them. In particular, there is a risk that doctors are prescribing medication to treat behaviour that is an expression of distress or a mode of 
communication rather than a mental disorder. Some people with intellectual disabilities have difficulty communicating their emotional needs and preferences. Therefore, doctors have a particular responsibility to ensure that they have fully assessed a person's potential to benefit from medication before they prescribe. They must also check that the anticipated benefits have occurred after they have prescribed.

David Branford, whose earlier work [5] influenced mine, co-edited this careful and strongly worded document produced by a team dominated by learning disability specialists.

With two provisos, this specialist report's advice is generally clear and strongly argues its case for greater prescribing caution. One reservation is that the advice lumps in autistic people with all other learning disabilities and generalizes that usual dosing practices will be fine for addressing mental illness when it occurs. Much anecdotal evidence says that autistic people often have atypical reactions including super sensitivity to drugs. As Defilippis and Wagner [14] suggest, "Children and adolescents with autism spectrum disorder appear to be more susceptible to adverse effects with medications; therefore, initiation with low doses and titrating [adjusting the dosage] very slowly is recommended." Also, neither they nor the Care Quality Commission (a public regulator of health and social services in England) note the need for staff medication training. The latter says (2017) "We will not consider it to be unsafe if providers can demonstrate that they have taken all reasonable steps to ensure the health and safety of people using their services and to manage risks that may arise during care and treatment." Since "reasonable steps" will of course include following instructions from doctors, this regulation can only have a protective impact if the doctors are also changing their practices: perhaps the current alliance between the NHS and the behaviourists (the autism and learning disability campaign Stopping Over Medication of People, or STOMP) may have the power to change those.

Sadly, it seems there has been little or no real progress this century-yet the very existence of these reports shows that the zeitgeist may finally have penetrated Bedlam. We may have helped let it in. 


\section{References}

1. Autism Europe. (1998). Draft code of good practice on prevention of violence against persons with autism. Brussels: Autism-Europe.

2. Kiernan, C., Reeves, D., \& Alborz, A. (1995). The use of anti-psychotic drugs with adults with learning disabilities and challenging behaviour. Journal of Intellectual Disability Research, 39(4), 263-274.

3. Shiwach, R. S., \& Carmody, T. J. (1998). Prolactogenic effects of risperidone in male patients-A preliminary study. Acta Psychiatrica Scandinavica, 98(1), 81-83.

4. Manchester, D. (1993). Neuroleptics, learning disability, and the community: Some history and mystery. BMJ, 307(6897), 184-187.

5. Branford, D. (1996). Factors associated with the successful or unsuccessful withdrawal of antipsychotic drug therapy prescribed for people with learning disabilities. Journal of Intellectual Disability Research, 40(4), 322-329.

6. Tranter, R., \& Healy, D. (1998). Neuroleptic discontinuation syndromes. Journal of Psychopharmacology, 12(4), 401-406.

7. Wing, L., \& Shah, A. (2000). Catatonia in autism spectrum disorders. British Journal of Psychiatry, 176, 357-362.

8. Murray, D. (1999). 'Potions, pills and human rights' in opening volume of Good Autism Practice (long version). Retrieved from http://www. autismusundcomputer.de/potions.en.html.

9. McConachie, H., Mason, D., Parr, J. R., Garland, D., Wilson, C., \& Rodgers, J. (2018). Enhancing the validity of a quality of life measure for autistic people. Journal of Autism and Developmental Disorders, 48(5), 1596-1611.

10. Ashcroft, R., Fraser, B., Kerr, M., \& Ahmed, Z. (2001). Are antipsychotic drugs the right treatment for challenging behaviour in learning disability?: The place of a randomised trial. Journal of Medical Ethics, 27(5), 338-343.

11. Brylewski, J., \& Duggan, L. (1999). Antipsychotic medication for challenging behaviour in people with intellectual disability: A systematic review of randomized controlled trials. Journal of Intellectual Disability Research, 43(5), 360-371.

12. Unwin, G., \& Deb, S. (2006). Your guide to taking medicine for behaviour problems: Easy read. University of Birmingham. Retrieved September from https://www.birmingham.ac.uk/Documents/college-les/psych/ld/ LDEasyReadGuide.pdf. 
13. Alexander, R., Branford, D., \& Devapriam, J. (2016). Psychotropic drug prescribing for people with intellectual disability, mental health problems andlor behaviours that challenge: Practice guidelines. (Faculty Report No. FR/ID/09). Retrieved from The Royal College of Psychiatry website: https://www. rcpsych.ac.uk.

14. DeFilippis, M., \& Wagner, K. D. (2016). Treatment of autism spectrum disorder in children and adolescents. Psychopharmacology Bulletin, 46(2), $18-41$.

Open Access This chapter is licensed under the terms of the Creative Commons Attribution 4.0 International License (http://creativecommons.org/licenses/by/ $4.0 /$ ), which permits use, sharing, adaptation, distribution and reproduction in any medium or format, as long as you give appropriate credit to the original author(s) and the source, provide a link to the Creative Commons license and indicate if changes were made.

The images or other third party material in this chapter are included in the chapter's Creative Commons license, unless indicated otherwise in a credit line to the material. If material is not included in the chapter's Creative Commons license and your intended use is not permitted by statutory regulation or exceeds the permitted use, you will need to obtain permission directly from the copyright holder.

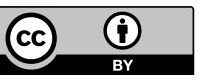

